\title{
Isolation, Structural Elucidation and Bioactivity Studies of Tropane Derivatives of Alkaloids from Seeds Extract of Datura Stramonium
}

\author{
Giday Gebregziabher Welegergs ${ }^{1,}{ }^{*}$, Kalyou Hulif ${ }^{1}$, Solomon Mulaw ${ }^{1}$, Haftu Gebretsadik ${ }^{1}$, \\ Berihu Tekluu", Ayalew Temesgen (Ph.D) ${ }^{3}$ \\ ${ }^{1}$ Department of Chemistry, College of Natural and Computational Science, Debrebirhan University, Debrebirhan, Ethiopia \\ ${ }^{2}$ Department of Chemistry, College of Natural and Computational Science, Aksum University, Aksum, Ethiopia \\ ${ }^{3}$ Department of Chemistry, College of Natural and Computational Science, Gondar University, Gondar, Ethiopia
}

Email address:

getgiday@gmail.com (G. G. Welegergs)

\section{To cite this article:}

Giday Gebregziabher Welegergs, Kalyou Hulif, Solomon Mulaw, Haftu Gebretsadik, Berihu Tekluu, Ayalew Temesgen. Isolation, Structural Elucidation and Bioactivity Studies of Tropane Derivatives of Alkaloids from Seeds Extract of Datura Stramonium. Science Journal of Chemistry. Vol. 3, No. 5, 2015, pp. 78-83. doi: 10.11648/j.sjc.20150305.11

\begin{abstract}
Datura stramonium (Solanaceae) is a plant species distributed throughout most parts of temperate regions of the world and is a noxious weed of cultivated cereal crops. The plant has medicinal value and is important in traditional medicine like the other species in the genus. The aim of this study was to isolate, purify and characterize the bioactive principle from the seeds of the plant. For isolation of the compound, the air dried seeds powder $(125 \mathrm{~g})$ of plant was soaked at room temperature for $12 \mathrm{hr}$ with $\mathrm{MeOH}(500 \mathrm{ml})$ and extracted using rotary evaporator. The crude extracts were showed a wide range of zones of inhibition against all the tested bacterial strains. The isolated and purified afforded white crystalline powder (TA) was subjected to spectral identification by IR, ${ }^{1} \mathrm{H}^{-} \mathrm{NMR},{ }^{13} \mathrm{C}-\mathrm{NMR}$, DEPT-135 and GC - MS. The isolated compound was concluded as 3-(3'-methoxytropoyloxy)-6-tigloyloxy -7-Hydroxy tropane.
\end{abstract}

Keywords: Datura Stramonium, Solanaceae, Antimicrobial, Alkaloids, Tropane, 3-(3'-Methoxytropoyloxy)-6-Tigloyloxy-7-Hydroxy Tropane

\section{Introduction}

Medicinal plants have been in use all over the world to treat various diseases including infections, cancer, inflammation, heart diseases etc. The use of natural products for treatment of all kind of diseases is due to their less harmful effects as compared to drugs synthesized in the laboratory ${ }^{1,2}$.

Datura stramonium is a widespread annual plant from the Solanaceae family. It is one of the widely well known folklore medicinal herb. It is a wild growing flowering plant and was investigated as a local source for tropane alkaloids which contain a methylated nitrogen atom $\left(\mathrm{N}-\mathrm{CH}_{3}\right)$ and include the anti-cholinergic drugs atropine and scopolamine. This plant is very toxic, causing hallucinations and delirium, which can even lead to madness. It is now used to treat asthma, and gastrointestinal problems, also aches, abscesses, arthritis, boils, headaches, hemorroids, rattlesnake bites, sprains, swellings, and tumors ${ }^{3,4}$.

The alkaloids content of datura stramonium has been emphasized by the phytochemical investigators dealing with the biological composition of various parts of the plant. Atropine, hyoscamine, and scopolamine are the tropane alkaloids of all species of the genus datura and their concentrations showed variations depending on species and on the part of the plant. Proteins, fats, fatty acids, reducing sugars, oxalates, nitrates, and tannin are among the chemical entities that have been described in the plant ${ }^{1,5,6}$.

\subsection{Chemistry of Tropane Alkaloids}

Tropane alkaloids are a class of alkaloids and secondary metabolites that contain a tropane ring in their chemical structure $^{7,8}$. The name tropane is given to the bicyclic saturated structure (N-methyl-8-azabicyclo[3.2.1] octane 1 figure 1, characteristic of a class of 200 alkaloids which are conveniently subdivided according to the number of carbons 
in the tropane skeleton and stereochemical features and bearing at least one hydroxyl group (in position 3), such prototypal structure can exist in two configuration $(\mathrm{C}-3$ epimeric) variations, for which common names tropine 2 and pseudotropine 3, tropinone 4 and 2-exo-carboxytropinone 5 are used ${ }^{9,10}$.
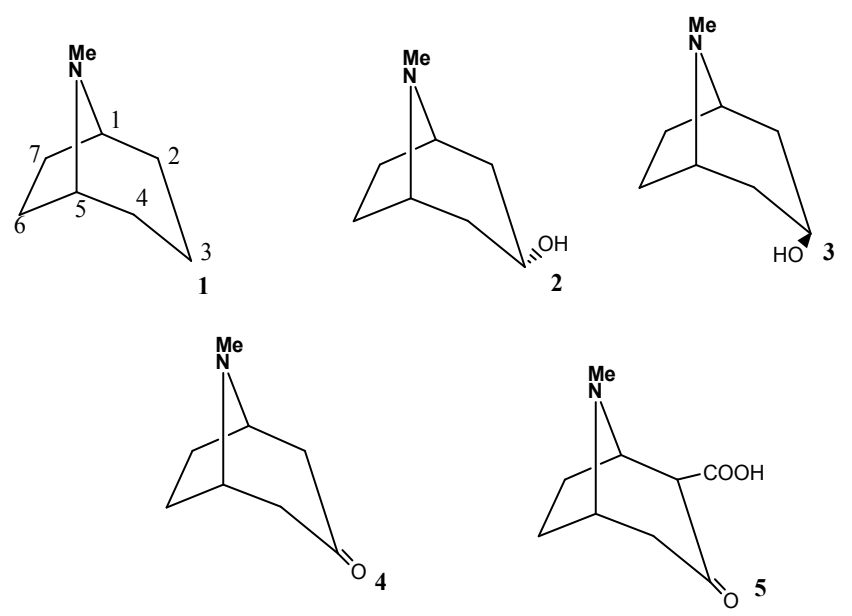

Figure 1. Tropane (1) and its derivatives.
The amino acids, ornithine, arginine, aspartic acid and tryptophan occur as precursor of alkaloids in plants. The main reactions in the biosynthesis of alkaloids are carboxylation, oxydative, desamination and transamination $11,12,13$.

In short, the main precursor of the bicyclic alkamine part is L-ornithine 6 converted to a diamine, putrescine 7 by a specific decarboxylase (OrnDC). Putrescine (which can be also obtained biogenetically from arginine) is mono-Nmethylated by transferase PMT and subsequently transformed into 4-N-methylaminobutanal by diamineoxidase (DAO). Next, spontaneous cyclization dehydration takes place, with formation of the common intermediate precursor, N-methyl- $\Delta-1$-pyrrolinium cation 8 from which nicotine, cocaine and tropane alkaloids can be formed. This monocyclic precursor is further transformed into a corresponding 4-carbon side chain $\beta$-ketoacid intermediate 9 by the action of two acetyl coenzymeA, (AcCoA) ester molecules. The oxobutanoic acid 10 can cyclize to exo-carboxytropinone 11 from which derivatives of tropine 12 and/ or pseudotropine 13 are subsequently formed ${ }^{14,15}$ (Scheme 1).<smiles>CC(C)CC(C)CN1CCC(C#CCCN)C1</smiles>
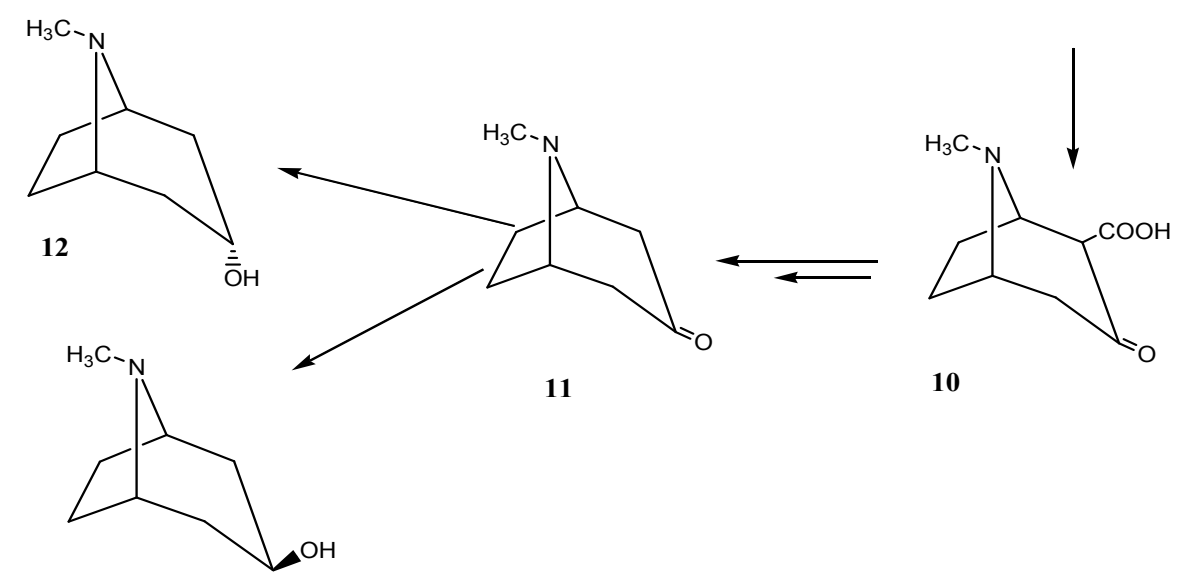

13

Scheme 1. Crucial steps in biosynthesis of tropines.

\subsection{Derivatives of Tropine}

Decarboxylation of L-pheylalanine14 leads to tropinone 16 from which tropines (17 \& 18) can be obtained by biotransformation or chemical reduction ${ }^{16,17}$.

The most important natural tropane alkaloids hyoscyamine (3- $\alpha$-hydroxytropane) 17 and scopolamine (3- $\beta$ hydroxytropane) 18 (Scheme 2) are esters of tropane-3 $\alpha$-ol and the 6-7 epoxide of tropane- $3 \alpha-\mathrm{ol}$ and tropic acid. Hyoscyamine, the principal alkaloid of the above mentioned plants is the ester of tropine with levorotatory $\{1(-)\}$ or $(S)$ tropic acid, which is believed to be biogenetically generated by skeletal rearrangement of phenyllactic acid 15 which in turn is derived from L-phenylalanine 14. The metabolic pathway from tropine phenyllactic ester, littorine 16, to tropic acid ester, hyoscyamine 17 (Scheme2) which involves the 1, 2-carboxy group shift, generally accepted by modern treatises on alkaloid biosynthesis ${ }^{14,18}$.

$6-\beta$-Hydroxytropine 18 (this compound is also known as anisodamine), generated by action of the enzyme hyoscyamine $6-\beta$-hydroxylase is a precursor to another alkamine, scopine, which contains an additional epoxide ring and constitutes a basic part of hyoscine 19. It is another 
important alkaloid with medicinal applications, which is an ester of levorotatory (-) tropic acid. Scopolamine 19 is the most valued tropane alkaloid, which found various medical applications from antiemesis to resuscitation, and also serves as a raw material in synthesis of the next generation drugs.
Minor tropane alkaloids contain tropine, nortropine or hydroxylated tropines as an alkamine part, and may be esterified in position C-3 with a variety of acids as, for example benzoic, cinnamic, tiglic, truxillic, isovaleric, methylbutyric, and others ${ }^{4,16,18,19}$.

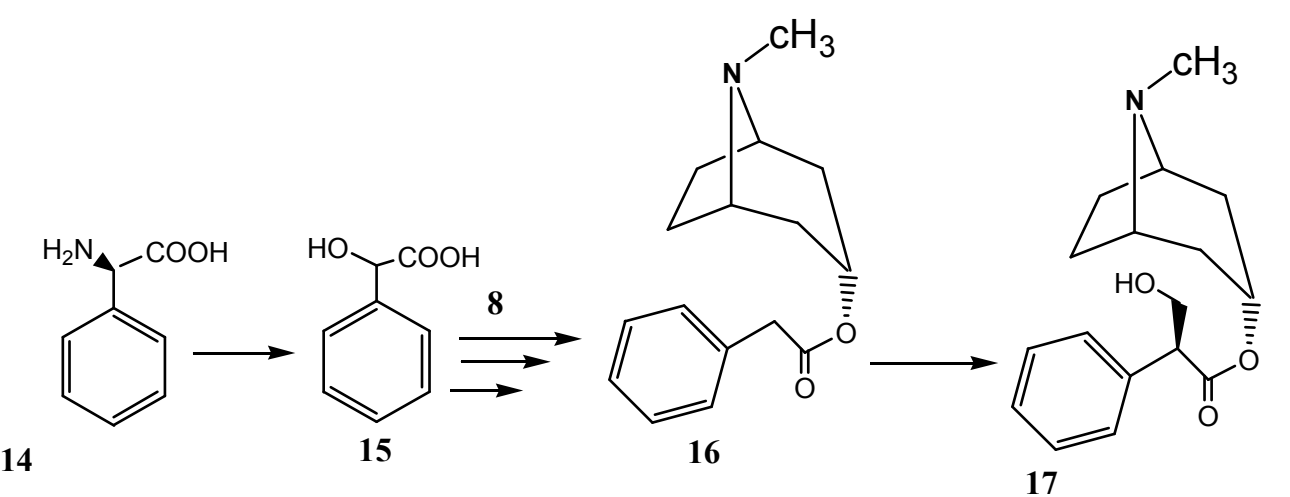

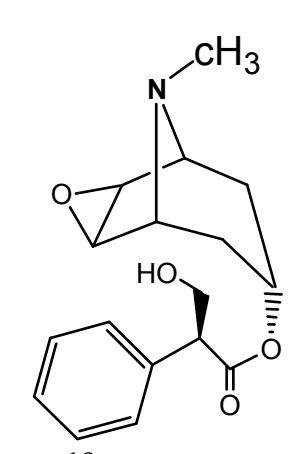

19

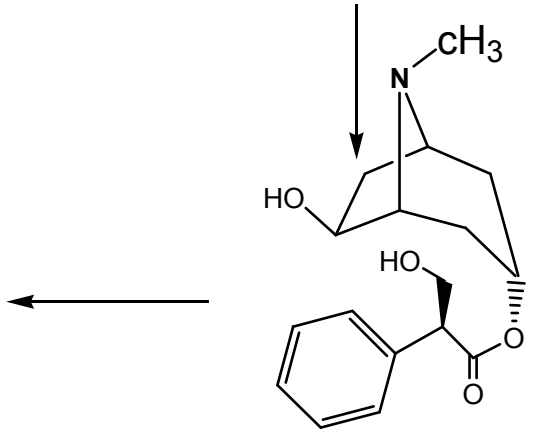

18

Scheme 2. Biosynthesis of tropic acid esters.

\section{Materials and Methods}

\subsection{Plant Material}

The plant material used in this study was collected in September, 2012, from Gondar city, Ethiopia. The tree is approximately $1.5 \mathrm{~m}$ in large, alternate, dark green leaves and sometimes with purple stem. The fruit is in the form of a spiny capsule, foliage has trumpet- shaped, flowers are hermaphrodite and its seeds are dark in color. The plant was taxonomically identified by Sameule sahile (Ph.D), Botany Department, Gondar University. The seed part of the plant was manually separated, air dried, powdered, weighed and stored in air tight container.

\subsection{Extraction and Isolation}

Air-dried and powdered Datura stramonium seeds (125 gm) were successively extracted with $\mathrm{MeOH}(500 \mathrm{ml})$ for $12 \mathrm{hr}$. The extract was concentrated and kept in the refrigerator. A small quantity of concentrated matter was dissolved in chloroform and this solution is spotted on TLC plates using precoated aluminium with silica gel $60 \mathrm{~F}_{254}$. Then the TLC plates were run by specific solvent system and viewed individually under UV light and also (5\%) sulphuric acid in methanol reagent. Through several pilot experiments it was found that the compound fractions were separated by the solvent system of chloroform and ethanol in the proportion of 9:1 \& 8:2. The chromatograms when developed in iodine chamber yielded eight to ten spots respectively and three spots at $\mathrm{Rf}(0.41,0.65 \& 0.90)$ becomes reddish brown.

Further purification is carried out over those components using column chromatography (merck silca gel 60 (70-230 mesh)) for isolation the active component. The column was run using hexane, chloroform, ethyl acetate and methanol by gradient elution technique. TLC was used to monitor the eluates. Similar fractions were pooled together. Additional purification is carried out using preparative TLC. Spots were identified, scraped and eluates using petroleum ether and chloroform as solvents.

Finally the isolated compound (TA) yielded a single spot when subjected to TLC using several solvent systems including chloroform: ethanol (9:1 \& 2:8), ethyl acetate: ethanol (9:1 \& 8:2), chloroform: ethyl acetate (4:1) and it showed to be homogenous compound. This isolated compound (TA) a white crystalline powder $(63 \mathrm{mg})$ with melting point $\left(134-137^{\circ} \mathrm{C}\right)$ was further subjected to IR, ${ }^{1} \mathrm{H}$ NMR (400MHz), 13C-NMR (100 MHz), DEPT-135 NMR and GC - MS to ascertain the chemical structure. 


\subsection{Antimicrobial Activities of the Extracts}

Following extraction, the crude extracts were collected and tested by using disc diffusion and agar well diffusion methods against gram positive bacteria (S. b hemolytic, Staph. aureus, S. dysenteriae and B. cereus) and gram negative bacteria (ATCC2923, Salmonella typhi ATCC9289, Pseudomonas aeruginosa ATCC27853, Klebsiella pneumonia ATCC7000603 and Escherichia coli ATCC2592).

The tested bacteria were prepared by mixing a few bacterial colonies $(1 \mathrm{ml})$ from exponential phase with $9 \mathrm{ml}$ of sterile nutrient broth and the turbidity was adjusted with 0.5 McFarland standards which is equivalent to $106-108 \mathrm{cfu} / \mathrm{ml}$. The sterile swab was dipped into the properly adjusted inoculum and swabbed on the Mueller Hinton agar (MHA) plates. Sterile cork borer (6 $\mathrm{mm}$ diameter) was used to bore holes in the plate and $100 \mu \mathrm{l}$ of the crude extracts at a concentration of $10 \mathrm{mg} / \mathrm{ml}$ was carefully dispensed into bored holes in triplicate. Filter paper sterilized with methanol was used as negative control. Extracts were allowed to diffuse for about 2 hrs before incubation and then incubated at $37^{\circ} \mathrm{C}$ for $24 \mathrm{hrs}$. After $24 \mathrm{hrs}$ of incubation, the presence of a zone of inhibition around each well was recorded.

\section{Result and Discussion}

\subsection{Characterization of Compounds}

This work reports the detection and characterization of one tropane alkaloid from seeds D.Stramonium via spectroscopy techniques (GC-MS, IR, ${ }^{1} \mathrm{HNMR},{ }^{13} \mathrm{CNMR}$ and DEPT-135).

The molecular ion $\left(\mathrm{M}^{+}\right)$peak at $\mathrm{m} / z 417$ corresponding to a molecular formula $\mathrm{C}_{23} \mathrm{H}_{31} \mathrm{NO}_{6}$. The base peak at $\mathrm{m} / z$ $\left[\mathrm{C}_{8} \mathrm{H}_{13} \mathrm{NO}\right]^{+}$and other prominent peaks at at $\mathrm{m} / \mathrm{z} 177$ $\left[\mathrm{PhCH}\left(\mathrm{CH}_{2} \mathrm{OCH}_{3}\right) \mathrm{CO}_{2}\right]^{+}, \quad 135 \quad\left[\mathrm{PhCHCH}_{2} \mathrm{OCH}_{3}\right]^{+}, \quad 104$ $\left[\mathrm{PhCHCH}_{2}\right]^{+}, 99 \quad\left[\mathrm{CH}_{3} \mathrm{CHC}_{\left.\left(\mathrm{CH}_{3}\right) \mathrm{CO}_{2}\right]^{+},} \quad 77 \quad\left[\mathrm{C}_{6} \mathrm{H}_{5}\right]^{+}, \quad 44\right.$ $\left[\mathrm{CO}_{2}\right]^{+}, 31\left[\mathrm{OCH}_{3}\right]^{+}$and $15\left[\mathrm{CH}_{3}\right]^{+}$was consistent with 3-(3'methoxytropoyloxy)-6-tigloyloxy-7-Hydroxy tropane and strongly suggested that the attachment of the ester function at C-3 and C- 6 of tropane alkaloids.

The molecular ion $\left(\mathrm{M}^{+}, 417\right)$ of this compound is with 128 mass units higher than those of hyoscyamine $\left(17, \mathrm{M}^{+}-289\right)$ indicating the presence of an additional methyl group at C-3', hydroxyl group at C-7 and tigloyl group at C-3.

The IR absorption spectrum showed a broad absorption peaks at $3373.6 \mathrm{~cm}^{-1}(\mathrm{O}-\mathrm{H}$ stretching $), 3201.83 \mathrm{~cm}^{-1}$ (aromatic hydrogen stretching), $2940.7 \mathrm{~cm}^{-1}$ and $2867.9 \mathrm{~cm}^{-1}$ (aliphatic C - H stretching), $1748.5 \mathrm{~cm}^{-1}$ (presence of easter groups), $1641.6 \mathrm{~cm}^{-1}(\mathrm{C}=\mathrm{C}$ stretching). Other absorption peaks includes $1377.20 \mathrm{~cm}^{-1}$ (O-H bending), $1458.21 \mathrm{~cm}^{-1}$ (C-H bending), $1038.7 \mathrm{~cm}^{-1}$ (cycloalkane bending) and $881.6 \mathrm{~cm}^{-1}$ (C - $\mathrm{H}$ unsaturated bending). These absorption frequencies resemble the absorption frequencies observed for 3-(3'methoxytropoyloxy)-6-tigloyloxy -7-Hydroxy tropane.

${ }^{1} \mathrm{H}-\mathrm{NMR}\left(\mathrm{CDCl}_{3}, 400 \mathrm{MHz}\right)$ spectrum has given signals, at $\delta$ $1.18(4 \mathrm{H}, \mathrm{t})$ where assigned to both $\mathrm{C}-2$ and $\mathrm{C}-4$ methylene protons. Other methylene proton signals appeared at $\delta 3.4(2 \mathrm{H}$ d) from C-3'. The methyl protons signals appeared at $\delta 1.75$
$(3 \mathrm{H}, \mathrm{s})$ and $2.12(3 \mathrm{H}, \mathrm{d})$ from $\mathrm{C}-5 "$ and $\mathrm{C}-4 "$ respectively. The tertiary amine methyl protons $\left(\mathrm{N}-\mathrm{CH}_{3}\right)$ signals appeared at $\delta$ $3.6(3 \mathrm{H}, \mathrm{s})$ and the methoxy protons $\left(\mathrm{O}-\mathrm{CH}_{3}\right)$ at $\delta 3.9(3 \mathrm{H}, \mathrm{s})$. Inspection of the ${ }^{1} \mathrm{H}-\mathrm{NMR}$ spectrum of the compound shows quaternary signal at $\delta 4.72(1 \mathrm{H}, \mathrm{q})$ are methine protons from $\mathrm{C}-3$ " and triplet signal at $\delta 3.6(1 \mathrm{H}, \mathrm{t})$ are methine protons which resulted from $\mathrm{C}-2$ '. Other methine protons appeared at $\delta$ $3.3(2 \mathrm{H}$, dd $)$ and at $\delta 3.5(1 \mathrm{H}$, dd $)$ from $\mathrm{C}-7$ and C-6 of cycloalkane respectively. A broad signal at $\delta 5.13$ indicated the presence of $\mathrm{O}-\mathrm{H}$ group attached to $\mathrm{C}-7$. Aromatic methine protons appear at $\delta 7.4(2 \mathrm{H}, \mathrm{d}) 7.53(1 \mathrm{H}, \mathrm{t})$ and $7.75(2 \mathrm{H}, \mathrm{dd})$ where assigned to ortho, para and metta part of the aromatic carbons respectively.

The ${ }^{13} \mathrm{C}$-NMR indicated that 17 types of carbon atoms exist with a molecule. The spectra showed two methyl carbons at $\delta$ 22.73 and 25.32 due to methyl of C-4" and C-5" respectively. Other methyl carbons appeared at $\delta 51.26$ and 60.21 due to amine methyl and methoxy carbons respectively. Two methylene carbon appeared at $\delta 29.95$ which represent $\mathrm{C}-2$ and $\mathrm{C}-4$ and at $\delta 53.24$ due to methylene of C-3'. The ${ }^{13} \mathrm{C}$ NMR indicated the presence one oxymethine at $\delta 80.86$ which resulted from C-3 and C-6, one hydroxyl methine at $\delta 69.86$, one methine at $\delta 41.72$ from $\mathrm{C}-2^{\prime}$ and two amine methine at $\delta$ 47.86 from $\mathrm{C}-1$ and $\mathrm{C}-5$. Conjugated olefinic methine also appeared at $\delta 153.45$. Quaternary carbon signal appeared at $\delta$ 115.31 from $\mathrm{C}-2$ '. Finally the spectrum indicated the presence of three aromatic methines at $\delta 123.06,124.18$ and 131.21 from ortho, para and metta respectively. Quaternary carbons signals observed at $\delta 138.42$ from quaternary benzene and at $\delta$ 166.20 from two ester carbonyl carbons (or from C-3 \& C-6).

Inspection of the DEPT-135 spectrum of the compound showed signals for 14 carbon atoms. Out of these signals 2 signals indicate the presence of methylene $\left(\mathrm{CH}_{2}\right)$ groups and the rest 12 signals for methines $(\mathrm{CH})$ and methyl $\left(\mathrm{CH}_{3}\right)$ groups. In DEPT-135 spectrum data are collected in such way that the resulting signal is either positive $\left(\mathrm{CH} \& \mathrm{CH}_{3}\right)$ or negative $\left(\mathrm{CH}_{2}\right)$ depending on the number of protons attached. In the proton decoupled ${ }^{13} \mathrm{C}$ NMR spectrum showed there are signals for 17 carbon atoms, while in the DEPT-135 spectrum signals were observed for 14 carbon atoms.

The difference in signals between the two spectra indicated the presence of 3 quaternary carbon atoms that are not normally observed in the DEPT-135 spectrum. The ${ }^{1} \mathrm{H}-\mathrm{NMR}$, ${ }^{13} \mathrm{C}-\mathrm{NMR}$ and DEPT-135 chemical shifts of the proposed structure are summarized in Table 1 below.

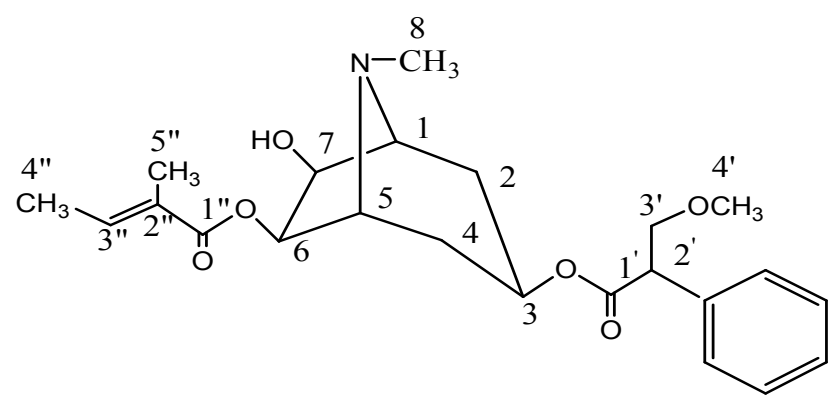

Scheme 3. The isolated compound 3-(3'- methoxytropoyloxy)-6-tigloyloxy 7-Hydroxy tropane (TA). 
Table 1. ${ }^{1} H-N M R,{ }^{13 C} N M R$ and DEPT-135 spectra data of compound the isolated compound.

\begin{tabular}{|c|c|c|c|}
\hline S.NO & ${ }^{13} \mathrm{C}-\mathrm{NMR}$ \&(ppm) & ${ }^{1} \mathrm{H}-\mathrm{NMR} \delta(\mathrm{ppm})$ & DEPT-135 \\
\hline C-1 andC-5 & 47.86 & $4.32(5 \mathrm{H}, \mathrm{t})$ & $\mathrm{CH}$ \\
\hline C-2andC-4 & 29.05 & $0.9-1.10(6 \mathrm{H}, \mathrm{m})$ & $\mathrm{CH}_{2}$ \\
\hline 1'and1" & 166.20 & & Quaternary \\
\hline C-3 andC-6 & 80.86 & $1.4(2 \mathrm{H}, \mathrm{s})$ & $\mathrm{CH}$ \\
\hline $\mathrm{C}-7$ & 69.86 & $3.3(1 \mathrm{H}, \mathrm{dd})$ & $\mathrm{CH}$ \\
\hline C-8 & 51.26 & $3.6(3 \mathrm{H}, \mathrm{s})$ & $\mathrm{N}-\mathrm{CH}_{3}$ \\
\hline $\mathrm{C}-2^{\prime \prime}$ & 115.31 & . & Quaternary \\
\hline C-3" & 153.45 & $4.72(1 \mathrm{H}, \mathrm{q})$ & $\mathrm{CH}$ \\
\hline C-4" & 25.32 & $2.12(3 \mathrm{H}, \mathrm{s})$ & $\mathrm{CH}_{3}$ \\
\hline C-5" & 22.73 & $1.75(3 \mathrm{H}, \mathrm{s})$ & $\mathrm{CH}_{3}$ \\
\hline $\mathrm{C}-2^{\prime}$ & 41.72 & $4.12(1 \mathrm{H}, \mathrm{dd})$ & $\mathrm{CH}$ \\
\hline $\mathrm{C}-3^{\prime}$ & 53.24 & $4.36(1 \mathrm{H}, \mathrm{dd})$ & $\mathrm{CH}_{2}$ \\
\hline C-4' & 60.21 & $3.9(3 \mathrm{H}, \mathrm{s})$ & $\mathrm{O}-\mathrm{CH}_{3}$ \\
\hline Ortho & 123.06 & $7.4(2 \mathrm{H}, \mathrm{d})$ & $\mathrm{CH}$ \\
\hline Para & 124.18 & $7.53(1 \mathrm{H}, \mathrm{t})$ & $\mathrm{CH}$ \\
\hline Metta & 131.21 & $7.75(2 \mathrm{H}, \mathrm{dd})$ & $\mathrm{CH}$ \\
\hline Quaternary benzene & 138.42 & & Quaternary \\
\hline
\end{tabular}

\subsection{Antimicrobial Activity the Crude Extract Against Standard Strains}

The antibacterial property of Datura stramonium extract using methanol solvent showed varying degree of response to wards the selected pathogens (Table 2). As the of present study proved, the crude extracts were showed a wide range zones of inhibition against the tested bacterial strains and this indicated that the crude extracts were indeed active to those bacteria.

Amongst the tested Gram-negative bacteria, K. Pneumonia was found to be the most sensitive, while E.coli was the most less senstive bacteria. In case of Gram-positive bacteria, $S$. aureus was the only sensitive strain.

The Gram negative isolates (P. aeruginosa, E. coli, $K$. Pneumoniae, S.bodii and S. typhi) in this study were high susceptible to the plants extracts than the Gram positive bacterial isolates ( $S$. b hemolytic, Staph. aureus, $S$. dysenteriae and $B$. Cereus).

The less susceptibility of the Gram positive isolates to the plants extracts have not proved the bacteria resistant but could mean that they need higher grade solvents for extraction or may necessitate higher concentrations than used in this study for more therapeutic activity.

On the general note, the work proved that the alkaloids from D. Stramonium are found to be more effective against gram negative bacteria than gram positive.

Table 2. Inhibition zones of the crude extract against Antimicrobial.

\begin{tabular}{|c|c|}
\hline Types of bacteria & Zone of inhibition (in $\mathrm{mm}$ ) \\
\hline \multicolumn{2}{|c|}{ Gram negative bacteria } \\
\hline 1. E. coli & $8 \mathrm{~mm}$ \\
\hline P. aeruginosa & $14 \mathrm{~mm}$ \\
\hline S. typhi & $9 \mathrm{~mm}$ \\
\hline 4. K. pneumonia & $15.5 \mathrm{~mm}$ \\
\hline 5. S.boydii & $11.5 \mathrm{~mm}$ \\
\hline \multicolumn{2}{|c|}{ Gram positive bacteria } \\
\hline 6. S. aureus & $9.5 \mathrm{~mm}$ \\
\hline 7. S. b hemolytic & 0 \\
\hline 8. dysenteriae & 0 \\
\hline 9. B. cereus & 0 \\
\hline
\end{tabular}

\section{Conclusion and Recommendation}

Phytochemical investigation on the methanol extract of the seed parts of Datura Stramonium afforded one compound; 3(3'-methoxytropoyloxy)-6-tigloyloxy-7-Hydroxytropane. The analyses of the results from bioactivity tests confirm the presence of active compounds which were extracted by methanol that has a wide range of zone of inhabitation against the tested bacterial strains. The alkaloids from D. Stramonium are found to be more effective against gram negative bacteria than gram positive.

Further works such as structure activity relationships and isolation to identify additional components and determine the mechanism of action of Datura Stramonium compounds would be recommended.

\section{Acknowledgements}

This work was funded by Debre Berhan University. The authors are thankful to Addis Ababa University and Gondar University for their cooperation in the characterization of the samples and biological studies respectively.

\section{References}

[1] Grzegorz G., \& Maria G., Tropane alkaloids as medicinally useful natural products and their synthetic derivatives as new drugs. Pharmacol Rep, 2008; 60(4), 439-463.

[2] Christen P., Tropane alkaloids, old drugs used in modern medicine. Bioactive Natural Products. Elsevier Science and Technology, 2000; 22, 717-749.

[3] Adekomi D. A, et.al., Exposure to smoke extract of datura stramonium leaf, some of its effects on heart, liver, lungs, kindney, and testes of male Sprague and dawley rats. Pharmacognosy and Phytotherapy, 2011; 3(5), 67-75. 
[4] Priyanka S. et al., Pharmacological properties of Datura stramonium L. as a potential medicinal tree. Asian Pac J Trop Biomed. 2012; 2(12), 1002-1008.

[5] Neeraj O., et al., rediscovering the medicinal properties of Datura species. Medicinal Plants Research, 2013; 7(39), 28852897.

[6] Nair R. and Chando S., Anticandida activity of Punica granatum exhibited in different solvents. Pharm. Biol, 2008; 43(1): 21-25.

[7] Jung D, et al., Synthesis of 2-substituted 8-azabicyclo [3.2.1] octan-3-ones in aqueous $\mathrm{NaOH}$ solution at low concentration. Bull Korean Chem Soc, 2006; 27(9), 1493-1496.

[8] Aqib S, and Mohib S. Phytochemistry, pharmacological and traditional uses of Daturastramonium L. Pharmacognosy and Phytochemistry, 2014; 2 (5): 123-125.

[9] Monica B., An analysis of Sorghum halepense's behavior in presence of tropane alkaloids from Datura stramonium extracts. Butnariu Chemistry Central Journal 2012; 6(1): 7582.

[10] Gaire BP, \& Subedi L., A review on the pharmacological and toxicological aspects of Datura stramonium L. Integrative Medicine, 2013; 11(2): 73-79.

[11] Griffin WJ, \& Lin GD., Chemotaxonomy and geographical distribution of tropane alkaloids. Phytochemistry, 2000; 53(6):623-637.
[12] Gachande BD, \& Khillare EM., In-vitro evaluation of Datura species for potential antimicrobial activity. Bioscience Discovery, 2013; 4(1), 78-81.

[13] Akharaiyi FC., Antibacterial, Phytochemical and Antioxidant activities of Datura metel. International Journal of Pharm Tech Research, 2011; 3(1), 478-483.

[14] Sweta VR., \& Lakshmi T., Pharmacological profile of tropane alkaloids,Chemical and Pharmaceutical Research, 2015; 7(5), 117-119.

[15] Nakaima K, \& Hashimoto T., Two tropine reductases that catalyze opposite stereospecific reductions in tropane alkaloid biosynthesis are localized in plant root with different cell specific patterns. Plant Cell Physiol, 1999; 40(11), 10991107.

[16] Oksman KM., Tropane and nicotine alkaloid biosynthesis novel approach towards biotechnological production of plant derived pharmaceuticals. Curr Pharm Biotechnol, 2007; 8(4), 203-210.

[17] Poupko JM, et al., The pharmacological properties of anisodamine. Applied Toxicology, 2006; 27(2), 116-121.

[18] Singh S., Chemistry, design and structure activity relationship of cocaine antagonist. Chem Rev, 2000; 100(3), 925-1024.

[19] Majewski M, \& Lazny R., Synthesis of tropane alkaloids via enantioselective deprotonation of tropinone. Organic Chemistry, 1995; 60(18), 5825-5830. 